\title{
Surgical and prosthetic management of maxillary odontogenic myxoma
}

Correspondence: Dr. Haroon Rashid

Email: drh.rashid@hotmail.com
Haroon Rashid ${ }^{1}$, Atif Bashir ${ }^{2}$

\section{ABSTRACT}

Odontogenic myxomas are uncommon tumors of comprising of $3 \%$ of all the tumors of odontogenic origin. They usually occur during the second and third decades of life and are more commonly seen in females. The current case report sheds light upon the surgical treatment of a myxoma of odontogenic origin in posterior maxilla of a young female patient. Prosthodontic rehabilitation stages are also briefly described following complete healing of the lesion after surgery.

Key words: Odontogenic myxoma, odontogenic tumors, maxillofacial prosthesis, prosthodontic rehabilitation

\section{INTRODUCTION}

World Health Organization classifies odontogenic myxomas (OMs) as nonmetastasizing, locally invasive benign tumors occurring both in maxilla and the mandible. They are relatively rare and represent around $3 \%$ of all the tumors of odontogenic origin and are frequently seen in the tooth bearing areas of the jaws. ${ }^{[1]}$ Their occurrence varies however; they are most frequently seen in second and third decades of life and are more common in females as compared to males. ${ }^{[2,3]}$ The lesion is usually asymptomatic showing a growth pattern which is mainly infiltrative. OM is capable of infiltrating the cortical bone causing its destruction, also expanding the cortical bone. ${ }^{[4]}$ Reoccurrence rates of $25 \%$ following surgical treatment have been reported and conservative treatment approach has been recommended. ${ }^{[5,6]}$

The origin of the lesion is unclear however; it has been reported that cells of the dental papilla or periodontal ligament may be involved. ${ }^{[7]}$ Usually, the tumor is radiolucent and may be unilocular or multilocular. The radiographic interpretation varies and could be described as well-defined corticated, noncorticated, poorly defined or diffused with the internal structure usually showing unilocular or multilocular radiolucency. ${ }^{[8]}$ Treatment of $\mathrm{OM}$ is usually surgical involving curettage. Since the lesions are usually infiltrative in nature, performing curettage is difficult and that is why the reoccurrence rates are higher. Cryotherapy has been shown to reduce the risk of reoccurrence if used as an adjunctive procedure. ${ }^{[9,10]}$

The head and face are two of the most important anatomical structures of the human body. It accommodates vital structures that are important for facial aesthetics. These include the eyes, nose, lips and muscles of facial expressions. Any defect occurring in these regions may significantly affect patient's well-being, life-style and social life. Patients with facial defects usually have problems of eating and swallowing, unclear speech, difficulty in cleaning the defects leading to foul smell, recurrent infections and facial collapse due to diplopia. The defects may result from a number of reasons which include trauma, infection and neoplasias. ${ }^{[11]}$ A defect which is of dento-alveolar origin is easily treated by conventional

How to cite this article: Rashid H, Bashir A. Surgical and prosthetic management of maxillary odontogenic myxoma. Eur J Dent 2015;9:277-83.

DOI: $10.4103 / 1305-7456.156842$ 
dentistry using a combination of fixed, removable and implant supported prosthesis.

Loss of mandible partially is difficult to treat as compared to partial loss of maxilla. This is mainly due to presence of tongue and other related musculature and the temporomandibular joint. Loss of mandibular bone particularly adds to the problems due to small denture bearing area resulting in a prosthesis that is very unstable. ${ }^{[12]}$ Functional and aesthetic rehabilitation in maxilla can be done with ease as compared to mandible. A maxillary denture/small obturator is usually required for smaller maxillary defects. For larger defects, a two peace hollow bulb obturator may usually be attached to the denture base for reconstruction. Osseointergrated dental implants have greatly improved the success of prosthodontic rehabilitation however; they may not be possible in larger defects due to subsequent anatomical limitations following removal of the hard tissues.

Maxillofacial prosthodontics is a division of dentistry in which removable prosthetic appliances are fabricated for the patients for restoring the form and function of facial structures. The current case report describes the surgical management of maxillary $\mathrm{OM}$ followed by the prosthodontic reconstruction using a removable maxillary obturator appliance.

\section{CASE REPORT}

A 22-year-old female patient presented to theoutpatient department of Oral and Maxillofacial Surgery at Ziauddin University Hospital complaining of an aching pain in the upper right quadrant. Inspection revealed slight redness of the upper right gingiva with sporadic spontaneous bleeding on probing. The patient had been previously assessed by a general dentist who carried out oral hygiene measures and referred the patient for a specialist opinion.

A complete history was taken, and examination performed. There was no significant past medical, surgical or dental history. She was fit and well, with vital signs within normal range, weighed approximately $65 \mathrm{~kg}$ and apyrexic. Extra oral examination revealed a minor facial swelling on the right zygomatic-maxillary region [Figure 1], with no skin discoloration or elevated temperature. A slight displacement of the right eye was noticed, without any limitation in ocular movement. Intra oral inspection revealed a dusky red swelling of the right upper gingivae extending from the right upper first molar

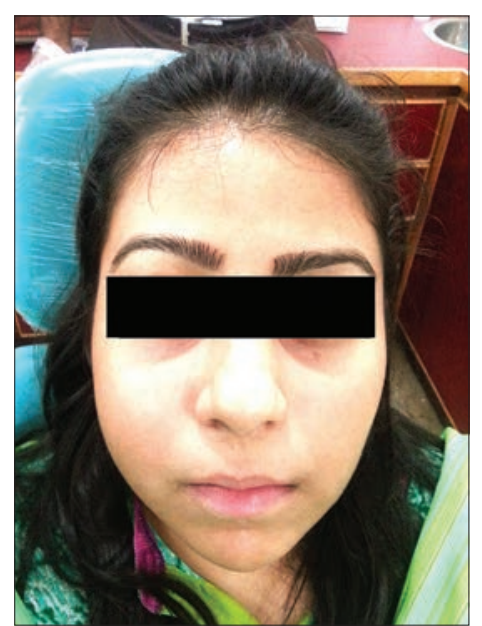

Figure 1: Preoperative anterior view showing facial swelling on right side

till the last standing wisdom tooth [Figure 2]. There was also a smooth homogenous, dusky red swelling in the right palatal region.

The patient was advised computed tomographic (CT) scans with axial and coronal sections in 3-4 mm slices along with an incisional biopsy of the affected area. Biopsy report confirmed an $\mathrm{OM}$ and $\mathrm{CT}$ images [Figures 3 and 4] revealed the mass extending from the mesial half of the upper bicuspid till the last standing tooth and from the roots of the upper right dentition till the naso-ethmoid regions, involving and displacing the orbital floor and lateral nasal wall and nasal septum.

Surgical resection followed by reconstruction with a prosthetic obturator was recommended to the patient.

\section{Surgical stage}

A Weber-Ferguson flap was raised with a Lynch extension (to gain access to the ethmoids). The skin incision was given with a number 15 blade [Figure 5], followed by local anesthetic injection, the subsequent deeper incision (from the muscle till the periosteum) was given with monopolar electrocautery. Skin hooks were used for skin retraction switched to cats-paw retractors for the deeper layers. Infra-orbital incision was given to expose the orbital floor. Wide tissue dissection was carried out to isolate and identify the surgical margins of the tumor. The infra-orbital and the angular artery were identified and ligated. The ethmoidal and nasal extent of the tumor was identified with gentle but firm tissue retraction [Figure 6]. Margins of the intraoral extent of the tumor were incised with a number 15 blade, from the distal aspect of the canine till the posterior limit of the hard palate. 


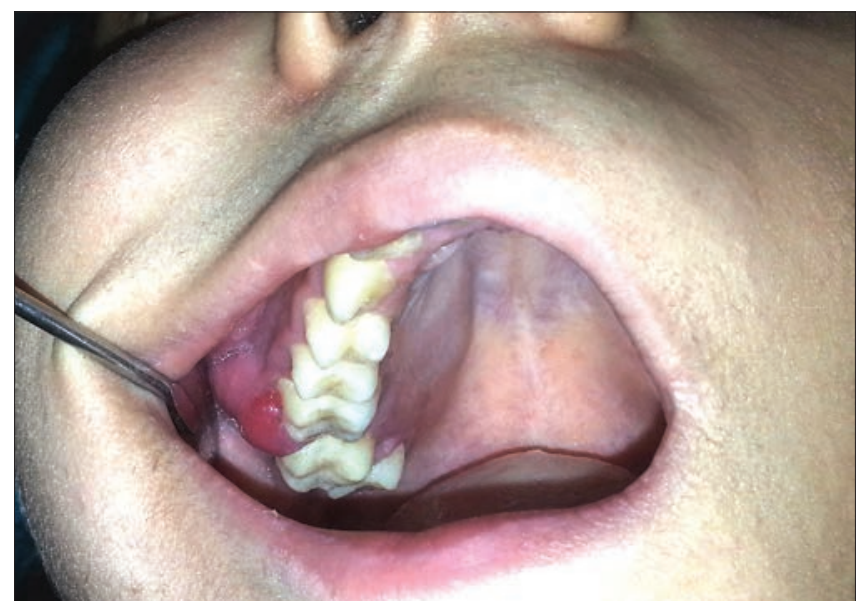

Figure 2: Preoperative intraoral view

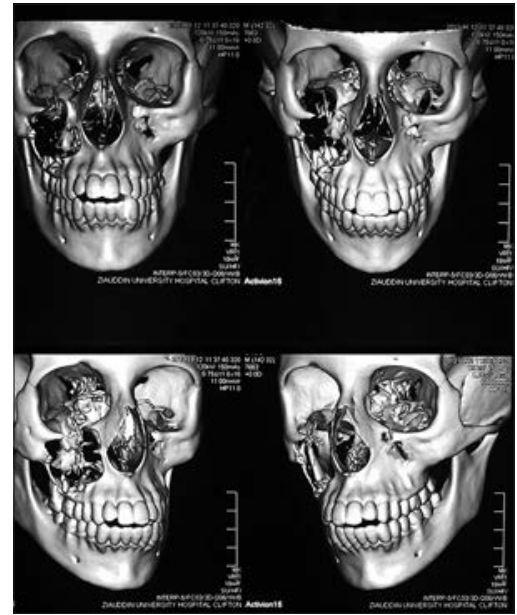

Figure 4: Three-dimensional computed tomographic scans

An oscillating saw was used to make osteotomies of bone (with a safe margin of $0.5-1 \mathrm{~cm}$ ) from the lateral nasal wall till the intraoral extent. The intra-orbital extent was identified and a decision was made to enucleate the lesion rather than perform an osteotomy due to the paper-thin bone (the orbital floor was found to be breached and virtually absent). After the facial aspect of the tumor was resected (with the help of osteotomies with an osteotome and saw), the ethmoidal mass was more visible and identifiable. Interior of the nasal cavity with the turbinates was cleared of the tumor mass followed by resection of the mass from the ethmoids [Figures 7 and 8].

A titanium mesh was adapted and conformed to act as an orbital floor, where it was secured with two $1.3 \mathrm{~mm}$ screws [Figure 9]. The soft palate was saved in its entirety. The cavity was washed with normal saline and after minor venous or arterial bleeder was cauterized, it was packed with Bismuth iodoform paraffin paste (BIPP) pack in ribbon gauze and the

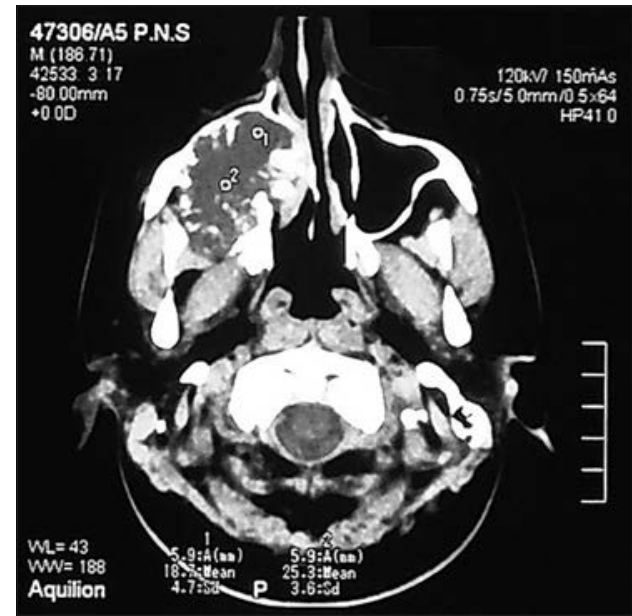

Figure 3: Computed tomographic scan

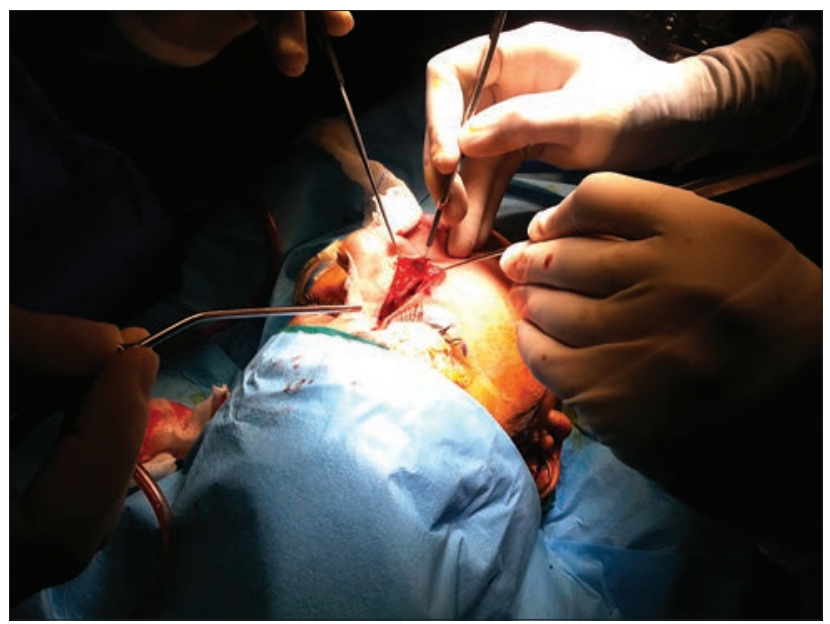

Figure 5: Incision at the start of surgery

flap was closed in 2 and 3 layers. A temporary acrylic plate was placed intra orally to hold the BIPP in place.

The patient was reviewed on the following postoperative day and 1-week thereafter, without any signs of complications. She was then subsequently reviewed after 1 -week, 1 -month, $3^{\text {rd }}$ month and 6 months [Figure 10]. During the $1^{\text {st }}$ month epiphora was noted from the right eye was noticed, for which the patient was advised to wear dark glasses to avoid light. She was referred to the department of prosthodontics so that an obturator appliance could be constructed.

\section{Prosthodontic stage}

The surgical resection included a part of the palate and posterior teeth of the affected side. When surgical resection of the tumor was carried out, an interim obturator plate was given to the patient which was worn for a period of 7 days. The patient was given a series of interim obturators till a satisfactory healing 


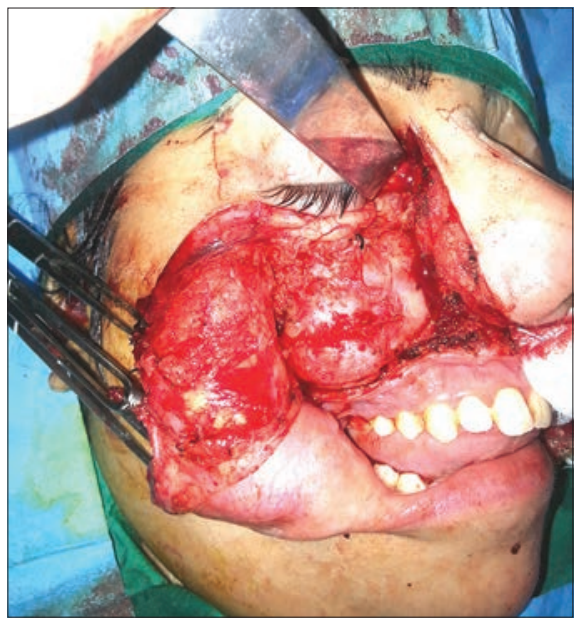

Figure 6: Clinical photograph showing extent of the tumor

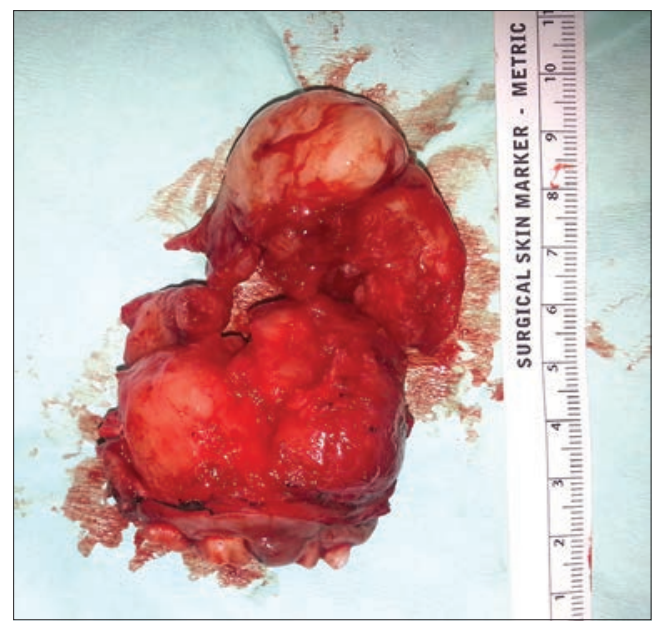

Figure 8: Size of the tumor on surgical skin marker

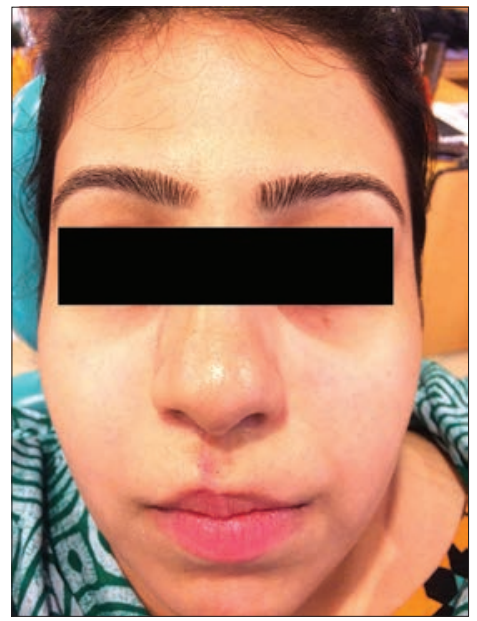

Figure 10: Postoperative anterior view of the face taken after 6 months

of the soft tissues [Figure 11] was achieved and an acrylic obturator with teeth was planned.

A perforated stock tray was selected for taking the initial impression of the upper arch. The stock tray was

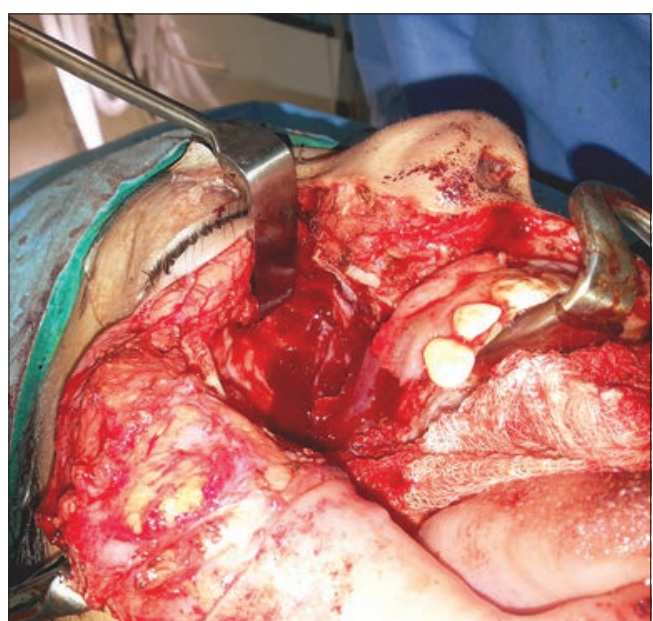

Figure 7: Clinical photograph after complete surgical resection

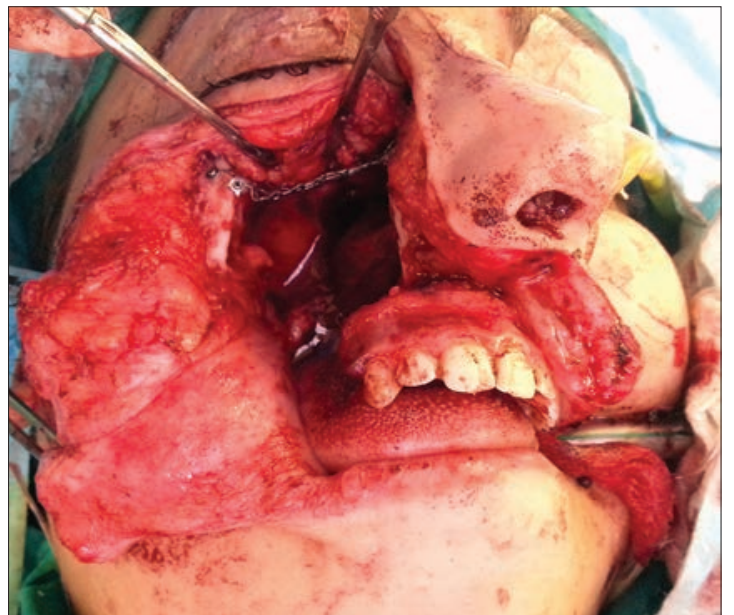

Figure 9: Titanium mesh placed to act as orbital floor

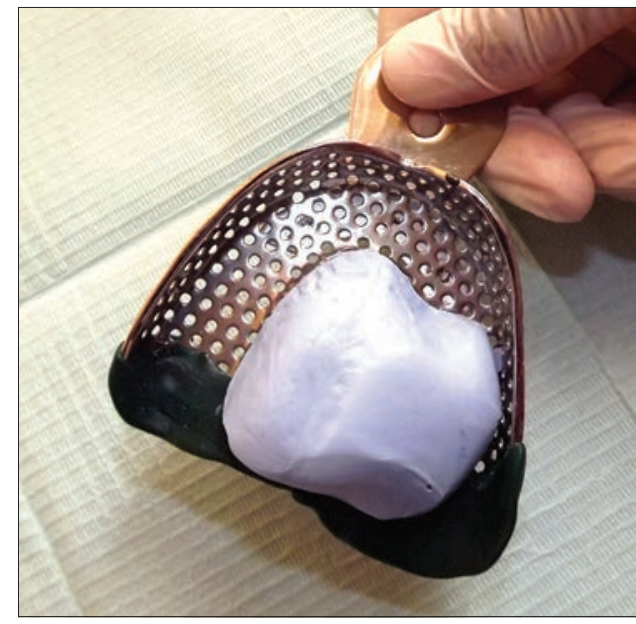

Figure 11: Modified stock tray

modified corresponding with the defect [Figure 12]. The primary impressions of the upper and the lower arches were recorded using irreversible hydrocolloid (Cavex, Holland BV) and study casts 
were obtained over which custom made acrylic resin trays were fabricated.

Tray adhesive (Caulk tray adhesive, Dentsply) was applied over custom made upper and lower trays and final impression of upper [Figure 13] and lower dentition were recorded using putty-wash technique with addition cured silicone (3M ESPE Express, 3M ESPE St.Paul, USA). Beading and boxing [Figure 14] of the impression was carried out and master casts obtained [Figure 15]. Face-bow (Whipmix Corporation, USA) transfer was carried out and centric relation was recorded. The upper and lower master casts with were mounted on a semi-adjustable articulator (Whipmix Corporation, USA) using the face-bow transfer.

The arrangement of the artificial teeth was carried out and the trial denture was checked intraorally. Aesthetics and function were checked before processing of the prosthesis and final denture [Figure 16] was inserted

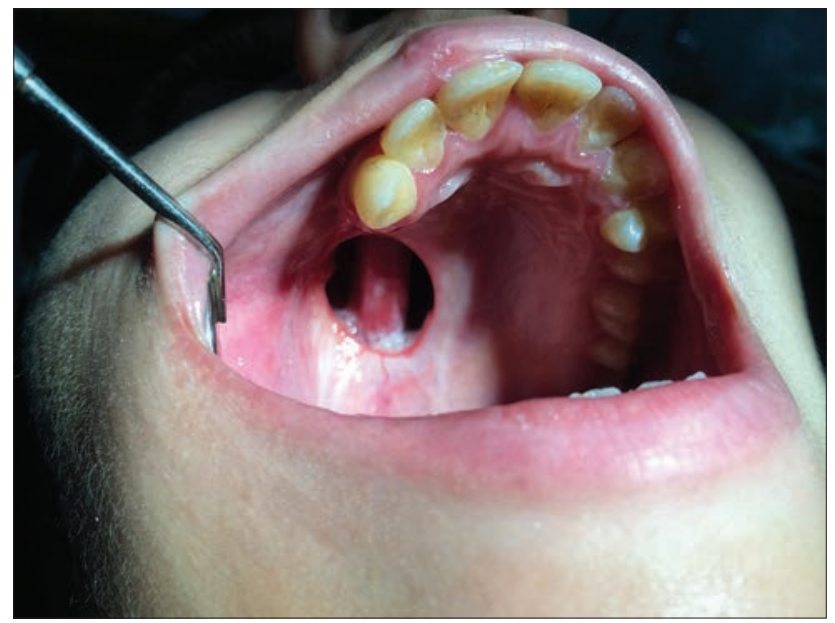

Figure 12: 6 months postoperative intraoral view showing the defect

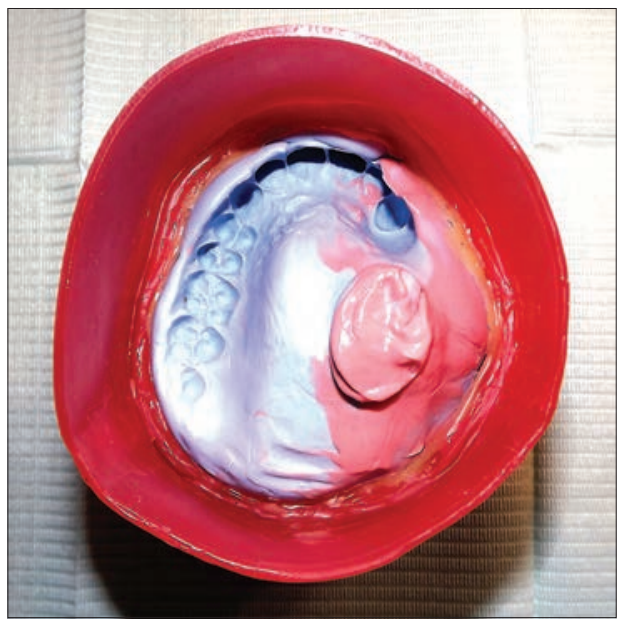

Figure 14: Beading and boxing of the final impression in the patient mouth [Figure 17]. The patient has been reviewed several times since then; she is satisfied and seemingly happy with her appearance and function. A hollow bulb obturator, with cast partial framework and required components is planned to be fabricated in future once the patient comfortably accepts the current denture.

\section{DISCUSSION}

Tumors of odontogenic origin are difficult to diagnose solely on the basis of radiographs since they do not show internal characteristic features. OMs, ameloblastomas and odontogenic cysts may present similar features radiographically. ${ }^{[13]}$ Results of a study of $21 \mathrm{OMs}$ based on the radiographic findings showed that myxomas are much more complex regarding their radiographic appearance. ${ }^{[14]}$ The authors reported that the unicystic lesions are generally smaller as compared to multi-cystic lesions and CT was more

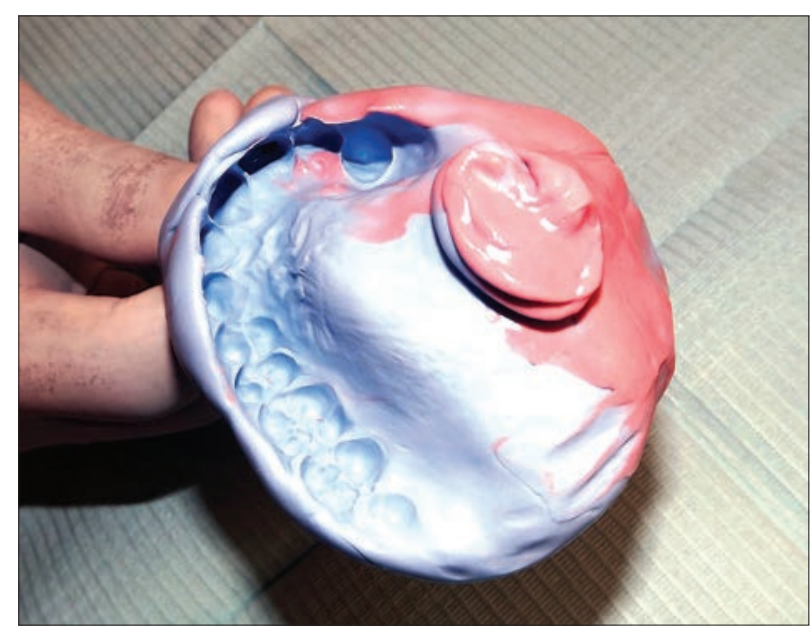

Figure 13: Final impression taken using addition cured silicone material

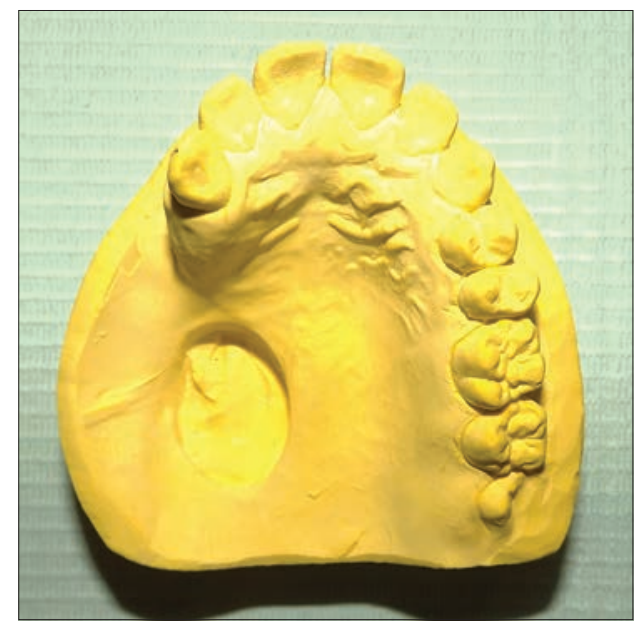

Figure 15: Master cast showing the defect 


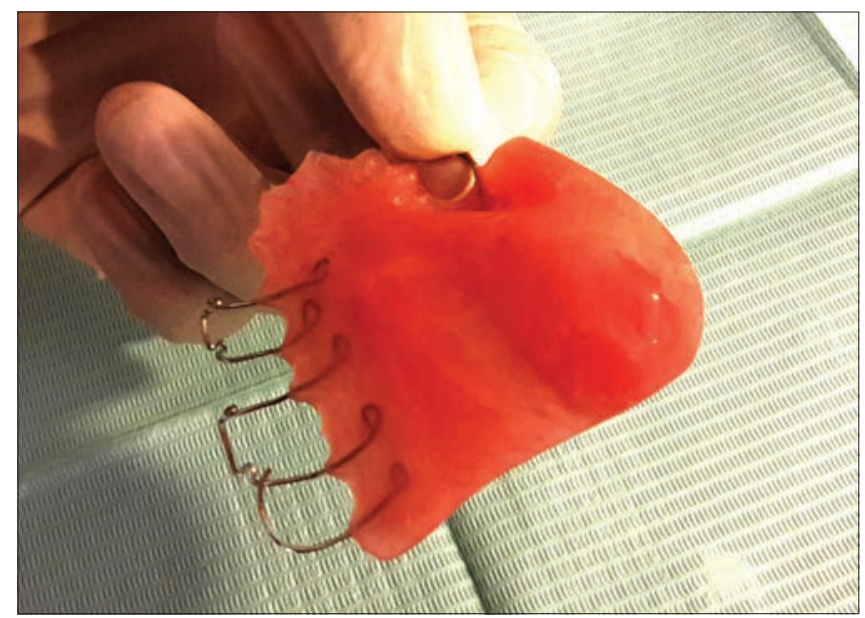

Figure 16: Removable acrylic obturator appliance

likely to display a cortex perforation. ${ }^{[15]}$ In the current clinical case, slices of CT images and three-dimensional images revealed the mass extending from the mesial half of the upper bicuspid till the last standing tooth and from the roots of the upper right dentition till the naso-ethmoid regions, involving and displacing the orbital floor and lateral nasal wall and nasal septum and biopsy was done for clinical co-relation and to confirm the diagnosis.

Magnetic resonance imaging (MRI) is shown to be the most useful modality for analyzing the internal structure of a lesion due to its superior contrast and multiplanar capabilities. Some studies have also mentioned that a dynamic MRI is also useful for differential diagnosis of various tumors. ${ }^{[16]}$ Due to the limited availability of MRI imaging as compared to the CT, complete characteristics of the OM have not been established satisfactorily. ${ }^{[4]}$ Therefore, additional studies mentioning the use of new available imaging techniques to improve the diagnosis of this lesion are required. Clinical and histological examination is shown to be very useful in diagnosing $\mathrm{OM}$ in different populations and is very helpful in clinical treatment planning. ${ }^{[17-19]}$

Due to high rates of recurrence of $\mathrm{OM}$, the question as to which type of treatment modality should be applied cannot be answered. The tumor is aggressive and the literature also states that surgery is the treatment of choice. ${ }^{[20,21]}$ When conservative treatment approaches like enucleation, curettage, and cryotherapy are performed, there is high chance of recurrence mainly due to the infiltrative growth pattern of tumor. However; there are several advantages of conservative treatment over more aggressive surgical options. The conservative management of myxoma by excision and curettage with liquid nitrogen cryotherapy is an

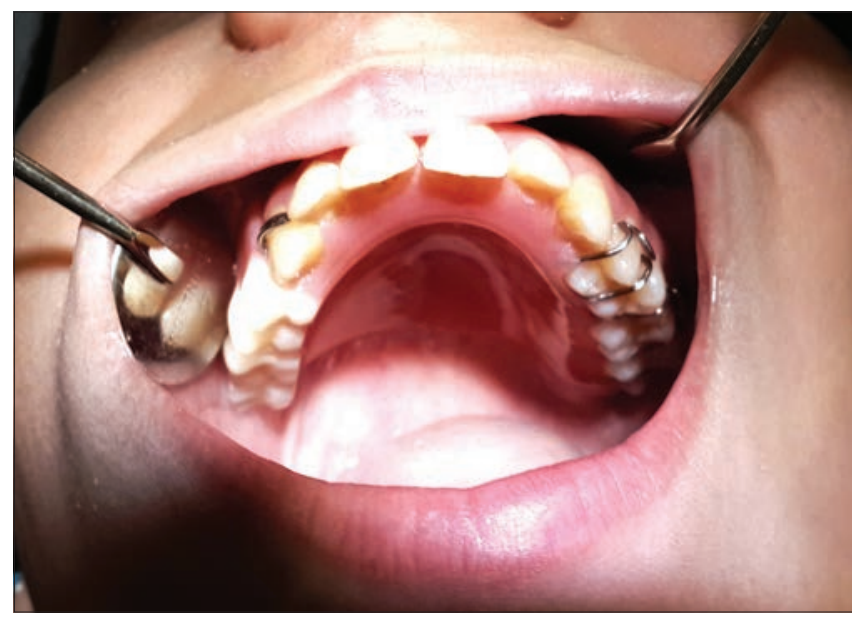

Figure 17: Intraoral view of the removable obturator appliance in place

alternative reliable method as liquid nitrogen will help in the elimination of any remaining neoplastic cells by bone devitalization. Liquid nitrogen does not affect the inorganic structure of the bone and thus has no effect on new bone formation. ${ }^{[9,10]}$ Boffano et al., ${ }^{[22]}$ stated that enucleation and curettage should be done when the OM lesions are smaller than $3 \mathrm{~cm}$, whereas segmental resection is recommended in cases when the lesions are significantly bigger in size. Irrespective of any treatment regime applied to treat $\mathrm{OM}$, regular clinical and radiographic follow-up must be done indefinitely and a minimum of 5 years of postoperative surveillance is required to confirm that the tumor has healed completely. ${ }^{[23]}$

Since the number of patients undergoing partial resection of maxilla is increasing, there was always a need to study and classify obturator designs. Aramany ${ }^{[24]}$ classified obturator design into six categories. His classification was based on the frequency of occurrence of the maxillary defects in 123 patients. After the surgical correction was carried out in the current case, the defect was unilateral and anterior teeth were maintained. This defect was thus categorized into Aramany Class II defect. This categorization is similar to that of a Kennedy Class II conventional removable partial design. The prosthesis provided in the current case was an acrylic interim bulb type obturator prosthesis which not only improved the speech and function, it also provided better comfort and confidence to the patient. In future, it is planned that a hollow bulb obturator, with cast partial framework and required components is provided to the patient.

Rehabilitation of patients with maxillectomy is very challenging and it is very difficult to achieve 
functional rehabilitation by means of removable prosthodontic rehabilitation alone. This is mainly because of instability of the prosthesis occurring due to excessive soft and hard tissue loss following surgery. Osseointegrated dental implants are necessary for functional rehabilitation of such patients however; it is not always possible due to certain anatomical limitations. ${ }^{[25]}$ Bone transport distraction is minimally invasive and has been shown to be a reliable procedure in many maxillofacial reconstructing techniques. ${ }^{[26-28]}$ Fujioka et al. ${ }^{[29]}$ successfully carried out transport distraction of posterior maxilla and placed implant supported prosthesis over three osseointegrated implants. With modern reconstructive techniques and availability of an increasing variety of reliable tissue flaps, many of the traditional problems of treating orofacial defects have been overcome.

\section{CONCLUSION}

Odontogenic myxomas are rare tumors of odontogenic origin with high recurring rates. CT and MRI are reliable in detecting the lesions and histopathological examination must be done to confirm the diagnosis. Treatment ranges from local excision, curettage to radical resection. Whichever treatment is carried out, regular clinical and radiographic follow-up must be done to ensure that the tumor has healed completely. Successful prosthodontic rehabilitation of patients with oro-facial defects depends on a multidisciplinary approach where clinicians from all dentistry disciplines must work in close consultation during several stages of treatment. This remains an area of dentistry which is very often neglected and must be addressed.

\section{REFERENCES}

1. Shao Z, Liu B, Zhang W, Chen X. Synchronous occurrence of odontogenic myxoma with multiple keratocystic odontogenic tumors in nevoid basal cell carcinoma syndrome. J Craniofac Surg 2013;24:1840-2.

2. Bast BT, Pogrel MA, Regezi JA. The expression of apoptotic proteins and matrix metalloproteinases in odontogenic myxomas. J Oral Maxillofac Surg 2003;61:1463-6.

3. Brannon RB. Central odontogenic fibroma, myxoma (odontogenic myxoma, fibromyxoma), and central odontogenic granular cell tumor. Oral Maxillofac Surg Clin North Am 2004;16:359-74.

4. Aquilino RN, Tuji FM, Nayene LM, Molina OF, Joo HY, Neto FH. Odontogenic myxoma in the maxilla: A case report and characteristics on CT and MR. Oral Oncol 2006;42:133-6.

5. Lo Muzio L, Nocini P, Favia G, Procaccini M, Mignogna MD. Odontogenic myxoma of the jaws: A clinical, radiologic, immunohistochemical, and ultrastructural study. Oral Surg Oral Med Oral Pathol Oral Radiol Endod 1996;82:426-33.

6. Katz JO, Underhill TE. Multilocular radiolucencies. Dent Clin North Am 1994;38:63-81.

7. Shafer WG, Hine MK, Levy BM. A Textbook of Oral Pathology. $4^{\text {th }}$ ed.
Philadelphia: W.B. Saunders; 1983. p. 295-7.

8. Altug HA, Gulses A, Sencimen M. Clinico-radiographic examination of odontogenic myxoma with displacement of unerupted upper third molar: Review of the literature. Int J Morphol 2011;29:930-3.

9. Pogrel MA. The use of liquid nitrogen cryotherapy in the management of locally aggressive bone lesions. J Oral Maxillofac Surg 1993;51:269-73.

10. Pogrel MA. The management of lesions of the jaws with liquid nitrogen cryotherapy. J Calif Dent Assoc 1995;23:54-7.

11. van den Heever JH, Sykes LM, Du Plessis F. The scope of maxillofacial prosthodontics. SADJ 2012;67:593-5.

12. Komisar A. The functional result of mandibular reconstruction. Laryngoscope 1990;100:364-74.

13. Hisatomi M, Asaumi J, Konouchi H, Yanagi Y, Matsuzaki H, Kishi K. Comparison of radiographic and MRI features of a root-diverging odontogenic myxoma, with discussion of the differential diagnosis of lesions likely to move roots. Oral Dis 2003;9:152-7.

14. Peltola J, Magnusson B, Happonen RP, Borrman H. Odontogenic myxoma - A radiographic study of 21 tumours. Br J Oral Maxillofac Surg 1994;32:298-302.

15. MacDonald-Jankowski DS, Yeung RW, Li T, Lee KM. Computed tomography of odontogenic myxoma. Clin Radiol 2004;59:281-7.

16. Takashima S, Noguchi Y, Okumura T, Aruga H, Kobayashi T. Dynamic MR imaging in the head and neck. Radiology 1993;189:813-21.

17. Etemad-Moghadam S, Chookhachizadeh S, Baghaii F, Alaeddini M. Odontogenic Myxoma: A study based on biopsy material over a 40-year period. J Contemp Dent Pract 2014;15:137-41.

18. Effiom OA, Adewole RA, Odukoya O. Clinicopathological characteristics of odontogenic myxoma in Nigerians. West Afr J Med 2011;30:255-61.

19. Simon EN, Merkx MA, Vuhahula E, Ngassapa D, Stoelinga PJ. Odontogenic myxoma: A clinicopathological study of 33 cases. Int J Oral Maxillofac Surg 2004;33:333-7.

20. Reddy SP, Naag A, Kashyap B. Odontogenic myxoma: Report of two cases. Natl J Maxillofac Surg 2010;1:183-6.

21. Spencer KR, Smith A. Odontogenic myxoma: Case report with reconstructive considerations. Aust Dent J 1998;43:209-12.

22. Boffano P, Gallesio C, Barreca A, Bianchi FA, Garzino-Demo P, Roccia F. Surgical treatment of odontogenic myxoma. J Craniofac Surg 2011;22:982-7.

23. Manne RK, Kumar VS, Venkata Sarath P, Anumula L, Mundlapudi S, Tanikonda R. Odontogenic myxoma of the mandible. Case Rep Dent 2012;2012:214704.

24. Aramany MA. Basic principles of obturator design for partially edentulous patients. Part I: Classification. J Prosthet Dent 1978;40:554-7.

25. Mukohyama H, Haraguchi M, Sumita YI, Iida H, Hata Y, Kishimoto S, et al. Rehabilitation of a bilateral maxillectomy patient with a free fibula osteocutaneous flap. J Oral Rehabil 2005;32:541-4.

26. Castro-Núñez J, González MD. Maxillary reconstruction with bone transport distraction and implants after partial maxillectomy. J Oral Maxillofac Surg 2013;71:e137-42.

27. Block MS, Baughman DG. Reconstruction of severe anterior maxillary defects using distraction osteogenesis, bone grafts, and implants. J Oral Maxillofac Surg 2005;63:291-7.

28. Feng Y, Fang B, Shen G, Xia Y, Lou X. Reconstruction of partial maxillary defect with intraoral distraction osteogenesis assisted by miniscrew implant anchorages. Oral Surg Oral Med Oral Pathol Oral Radiol Endod 2010;110:e1-7.

29. Fujioka M, Kanno T, Mitsugi M, Sukegawa S, Furuki Y. Oral rehabilitation of a maxillectomy defect using bone transport distraction and dental implants. J Oral Maxillofac Surg 2010;68:2278-82.

\begin{tabular}{|l|l|}
\hline \multicolumn{2}{|c|}{ Access this article online } \\
\hline Quick Response Code: & Website: \\
& www.eurjdent.com \\
\hline
\end{tabular}

